\title{
ANALYSIS OF SELF-CARE STRATEGIES AMONG NURSES IN SOUTHERN POLAND - A CROSS-SECTIONAL SURVEY
}

\author{
BEATA BABIARCZYK and DANUTA STERNAL \\ University of Bielsko-Biała, Bielsko-Biała, Poland \\ Department of Nursing, Faculty of Health Sciences
}

\begin{abstract}
Objectives: This study aimed to explore the self-care strategies undertaken by Polish nurses, and more specifically: to assess the participants' selfcare strategies; to check self-medication patterns in the study group; and to analyze compliance with medical recommendations regarding pharmacotherapy. Material and Methods: A quantitative and cross-sectional survey was conducted to examine the phenomenon of interest. The study employed a questionnaire survey with an independently designed questionnaire as a research tool. A total of 446 registered nurses taking part in different professional training courses for nurses in January-June 2018 who agreed to participate were included in the study. Results: The findings of this study reveal generally poor self-care strategies and compliance with medical recommendations among Polish nurses. The most frequent health behaviors among the surveyed nurses were caring for personal hygiene and a healthy diet. About $31 \%$ of the nurses confirmed supplements use. The most common reasons for taking supplements concerned the prevention of vitamin and mineral deficiencies (77.5\%), and boosting of the immune system (49.3\%). The most popular supplements included packs of vitamins $(57.2 \%)$, single vitamin $\mathrm{D}_{3}(33.3 \%)$ and magnesium (31.2\%). The vast majority of participants (79.8\%) took some kind of over-the-counter drugs (OTCs) in the last 6 months, most often painkillers and flu medications, relying most frequently on the information included on the drug leaflets. The analysis showed a statistically significant relationship between declared OTC use and age, marital status, years of professional experience and economic status. Overall, $26.9 \%$ of the study participants declared the use of both supplements and OTCs, while $16.4 \%$ of the participants used neither supplements nor OTCs. Conclusions: Self-care strategies undertaken by nurses should be seen as an essential factor in their positive therapeutic relationship with patients. The ageing nursing workforce should make all of us increasingly aware that their self-care needs will increase as well. Int J Occup Med Environ Health. 2022;35(1):13-25
\end{abstract}

Key words:

nursing staff, health behavior, dietary supplements, self-care, non-prescription drugs, medical compliance

\section{INTRODUCTION}

Self-care is a common practice and a reality in most people's everyday lives. During recent decades, it has also constituted the basic level of healthcare in every society $[1,2]$. According to the World Health Organization (WHO), the modern idea of healthcare is based on the active participation of all citizens in the shaping of health policy and in direct actions undertaken for their own health. The definition of self-care has evolved over recent years.
The oldest and probably most cited definition of selfcare is that provided by the WHO in 1983. Later, in 1998, the definition of self-care was modified by the WHO and for the first time the concept of self-medication was taken into account: "Self-care is what people do for themselves to establish and maintain health, and to prevent and deal with illness. It is a broad concept encompassing hygiene (general and personal), nutrition (type and quality of food eaten), lifestyle (sporting activities, leisure, etc.), environ-

Received: November 29, 2020. Accepted: April 21, 2021.

Corresponding author: Beata Babiarczyk, University of Bielsko-Biala, Department of Nursing, Faculty of Health Sciences, Willowa 2, 43-309 Bielsko-Biala, Poland (e-mail: bbabiarczyk@ath.bielsko.pl). 
mental factors (living conditions, social habits, etc.), socio-economic factors (income level, cultural beliefs, etc.) and self-medication" [3].

Self-care is primarily aimed at healthy people and refers to the prevention of diseases. However, it is also significant for people with existing ailments or even chronic diseases in which self-medication is an important part of the treatment. Self-medication means rational and responsible use of supplements or over-the-counter drugs (OTCs), where necessary in collaboration with the support of health professionals $[3,4]$.

Health professionals, including nurses, need to educate patients by motivating them to change their unhealthy behaviors and gain confidence in adopting self-care. Leading by example is one of the duties of all healthcare professionals $[2,5]$. Indisputably, it can have a great impact on patient outcomes, but what is actually known about how nurses take care of themselves? It is known that they work hard in a variety of healthcare settings, often having more than one job, and that their work can be enormously tiring, physically and otherwise [6-8]. What is also known is that nurses tend to be givers, people who naturally put the needs of others before their own on a daily basis. They often have difficulty balancing their work and their private lives. During a typical workday they strive to follow all procedures and routines, to ensure patients' safety, and to reduce the risk of a deterioration in the patients' condition. When they are off work, they are also striving to manage their family or private problems.

On May 1, 2017, ANA Enterprise (a union of companies that comprise the American Nurses Association: the American Nurses Association, the American Nurses Credentialing Center, and the American Nurses Foundation) launched a bold initiative - the Healthy Nurse, Healthy Nation ${ }^{\mathrm{TM}}$ (HNHN) Grand Challenge. This initiative aimed to transform the health of the nation by first improving the health of its 4 million registered nurses. Ongoing data from the Healthy Nurse ${ }^{\circledR}$ Survey showed an urgent need to improve nurses' health, particularly in the areas of physical activity, nutrition, rest, safety, and quality of life [9]. Taking into consideration the fact that nurses handle various types of medicines on a daily basis, and have knowledge about and easy access to them, they might be tempted to use medications to cope with their daily lives [7]. Furthermore, according to previous research, the typical consumer of almost all types of dietary supplements and OTC medicines is a woman around 40 years old, well-educated, with a family $[10,11]$. Most Polish nurses fit this profile.

The literature often offers insights into certain areas of self-care, specifically self-medication strategies in different populations, yet little is known about the strategies undertaken by nurses. Thus, this study aimed to explore the self-care strategies undertaken by Polish nurses, and more specifically:

- to assess the participants' self-care strategies,

- to check self-medication patterns in the study group,

- to analyze compliance with medical recommendations regarding pharmacotherapy.

\section{MATERIAL AND METHOD}

\section{Sample and procedure}

A quantitative and cross-sectional survey was conducted to examine the phenomenon of interest. All registered nurses taking part in different professional training for nurses, such as specialized training, qualifying courses and specialized courses organized by 2 authorized training centers in the period of January-June 2018 ( $\mathrm{N}=482)$ were invited to the study. After being informed of the purpose of the study, a sample of 450 registered nurses agreed to participate. Researchers distributed questionnaires to the participants immediately after training and completed questionnaires were deposited in a closed box. Due to errors in filling in the forms (skipped questions or sections of the questionnaire left incomplete), 4 questionnaires were rejected, while 446 of them were qualified to the study. 


\section{Research tool}

For the purpose of this study, a specially designed questionnaire was used. Each questionnaire was composed of 3 main sections: 1) a description of the questionnaire; 2) general information about the respondents ( 10 items); and 3 ) the main text (20 items). The first section contained information about the aim of the study and a glossary of terms (supplements, OTCs). For the purposes of this research, according to the Polish Act on Food Safety and Nutrition, dietary supplements refer to "foodstuffs that are to enrich our daily diet with ingredients insufficiently supplied in the meals we eat. They are a concentrated source of vitamins, minerals or other substances with a nutritional or physiological effect." The definition is consistent with Directive 2002/46/EC of the European Parliament [12-14]. Further, OTCs are defined as medicines sold directly to a patient without a prescription from a healthcare professional $[15,16]$. In the second section, the respondents were asked to answer 10 questions regarding their personal and workplace data. The third section included questions regarding self-care strategies undertaken by the respondents, their compliance with medical recommendations, and supplements and OTC use.

\section{Ethical considerations}

The study was performed in accordance with the ethical standards laid down in the Declaration of Helsinki, and the Scientific Ethics Committee at the University of Bielsko-Biala granted its permission for the study to be carried out (No. 2018/07/05/2). Participation was voluntary and anonymous, and the participants gave their informed consent to be involved in the study by completing the questionnaires. They were also instructed that they could withdraw from the study at any time.

\section{Data analysis}

All data was analyzed and verified statistically using the R program (R Project for Statistical Computing, v. 3.5.5), the PSPP program and MS Office 2019. Quantitative fea- tures were presented with the arithmetic mean and standard deviation. For qualitative features, $\chi^{2}$ test was used to assess the heterogeneity of answers in the groups defined by socio-economic and occupational variables. P-values of $<0.05$ were considered significant.

\section{RESULTS}

\section{Sample characteristics}

In total, 440 women $(98.7 \%)$ and 6 men $(1.3 \%)$ took part in the study. The average age of the participants was $40.6 \pm 10.3$ years (22-67 years) and their average professional experience was $17.6 \pm 11.2$ years ( $0-40$ years). In Table 1, an overview of the participants' professional characteristics is presented.

The majority of the participants stated that they did not suffer from any chronic diseases (74\%). The disorders most frequently enumerated by the rest of the study participants were metabolic diseases (37.1\%) and those of the circulatory system (35.3\%). The vast majority of the study participants were satisfied with their general health status ("very good" - 19.5\%, "good" - 63\%) or assessed it as neutral (16.4\%). As far as the self-assessed economic status is concerned, the majority of the participants stated that it was good (57.1\%). Every third participant assessed it as average (32.3\%) and every tenth as excellent $(9.7 \%)$, while 3 participants $(0.7 \%)$ stated that it was below average, and $1(0.2 \%)$ that it was poor. In addition, $16.8 \%$ of the study participants reported taking medications on a permanent basis.

\section{Self-care strategies}

As far as maintaining health and strategies for its improvement are concerned, the vast majority of the study participants stated that they cared about personal hygiene (84.3\%) and ate healthily (61.7\%). More than half of the study group pointed to a limited use of stimulants like coffee, alcohol, cigarettes, etc. (55.8\%) or active recreation (52.7\%). The other strategies chosen by the participants 
Table 1. Participants' professional characteristics based on the survey conducted among Polish nurses taking part in different professional postgraduate training for nurses, in the period of January-June 2018

\begin{tabular}{|c|c|}
\hline Variable & $\begin{array}{c}\text { Participants } \\
\left(\mathrm{N}=446^{*}\right) \\
{[\mathrm{n}(\%)]}\end{array}$ \\
\hline \multicolumn{2}{|l|}{ Education } \\
\hline secondary nurse education & $118(26.5)$ \\
\hline Bachelor's degree in nursing & $217(48.7)$ \\
\hline Master's degree in nursing & $111(24.8)$ \\
\hline \multicolumn{2}{|l|}{ Job position $\left(\mathrm{N}=438^{*}\right)$} \\
\hline manager & $2(0.5)$ \\
\hline head nurse & $36(8.2)$ \\
\hline nurse & $379(86.5)$ \\
\hline other & $21(4.8)$ \\
\hline \multicolumn{2}{|l|}{ Professional experience } \\
\hline$\leq 10$ years & $146(32.7)$ \\
\hline $11-20$ years & $84(18.8)$ \\
\hline $21-30$ years & $169(37.9)$ \\
\hline$>30$ years & $47(10.5)$ \\
\hline \multicolumn{2}{|l|}{ Work settings $\left(\mathrm{N}=442^{*}\right)$} \\
\hline hospital & $354(80.1)$ \\
\hline primary care & $41(9.3)$ \\
\hline long-term care & $10(2.3)$ \\
\hline ambulatory & $13(2.9)$ \\
\hline other & $24(5.4)$ \\
\hline \multicolumn{2}{|c|}{ Specialization in nursing $\left(\mathrm{N}=442^{*}\right)$} \\
\hline yes & $42(9.5)$ \\
\hline no & $400(90.5)$ \\
\hline
\end{tabular}

* The difference between the number of participants is due to the lack of responses given.

were: healthy sleep of good quality and adequate duration (38.8\%), regular lifestyle (29.6\%), adherence to prescribed medications (24.4\%), regular health screening (20.9\%), and a low stress level (20\%). Some participants mentioned additional strategies such as good relationships with loved ones, positive thinking or meditation (3.8\%). The median number of declared healthy behaviors was 4
$(0-10)$. Home treatment options and remedies used by the participants included honey (37.8\%), herbs (36.7\%), hot and cold therapy (19.8\%), massages (17.7\%), and home remedies for flu and coughs (8.6\%). The methods used by the respondents when there was a deterioration in their health are presented in Table 2, alongside statistically important socio-demographic variables.

\section{Compliance with medical recommendations regarding pharmacotherapy}

The analysis revealed that half of the participants (50.9\%) "sometimes" bought all the medicines prescribed by their doctor, and 35.4\% did it "always." The participants who admitted not buying all medications prescribed by their doctor provided the following explanations: fear of potential side effects (50\%); improved health in the meantime (50\%); bad finances (41.2\%); too many prescribed medicines (29.4\%); some of the prescribed medicines already stored at home (17.6\%); and the replacement of the prescribed medicines by home remedies (11.8\%). Among all analyzed socio-demographic and professional variables, only the respondents' age and professional experience influenced the results (Table 3).

The vast majority of the study participants stated that they took the medicines prescribed by their doctor regularly ("always" - 46.2\%; "sometimes" - 49.1\%). Again, only the respondents' age and professional experience influenced the results (Table 3).

The majority of the respondents admitted "sometimes" taking all medicines prescribed by their doctor (56.9\%) and one-third of them confirmed doing it "always" (31.7\%). The characteristics of the statistically significant relationship between responses to this question and the participants' age and professional experience is presented in Table 3.

The majority of the respondents denied modifying or discontinuing their medicines by themselves ("rather not" - 52.1\%; "definitely not" - 15.6\%). However, $21.7 \%$ admitted that 

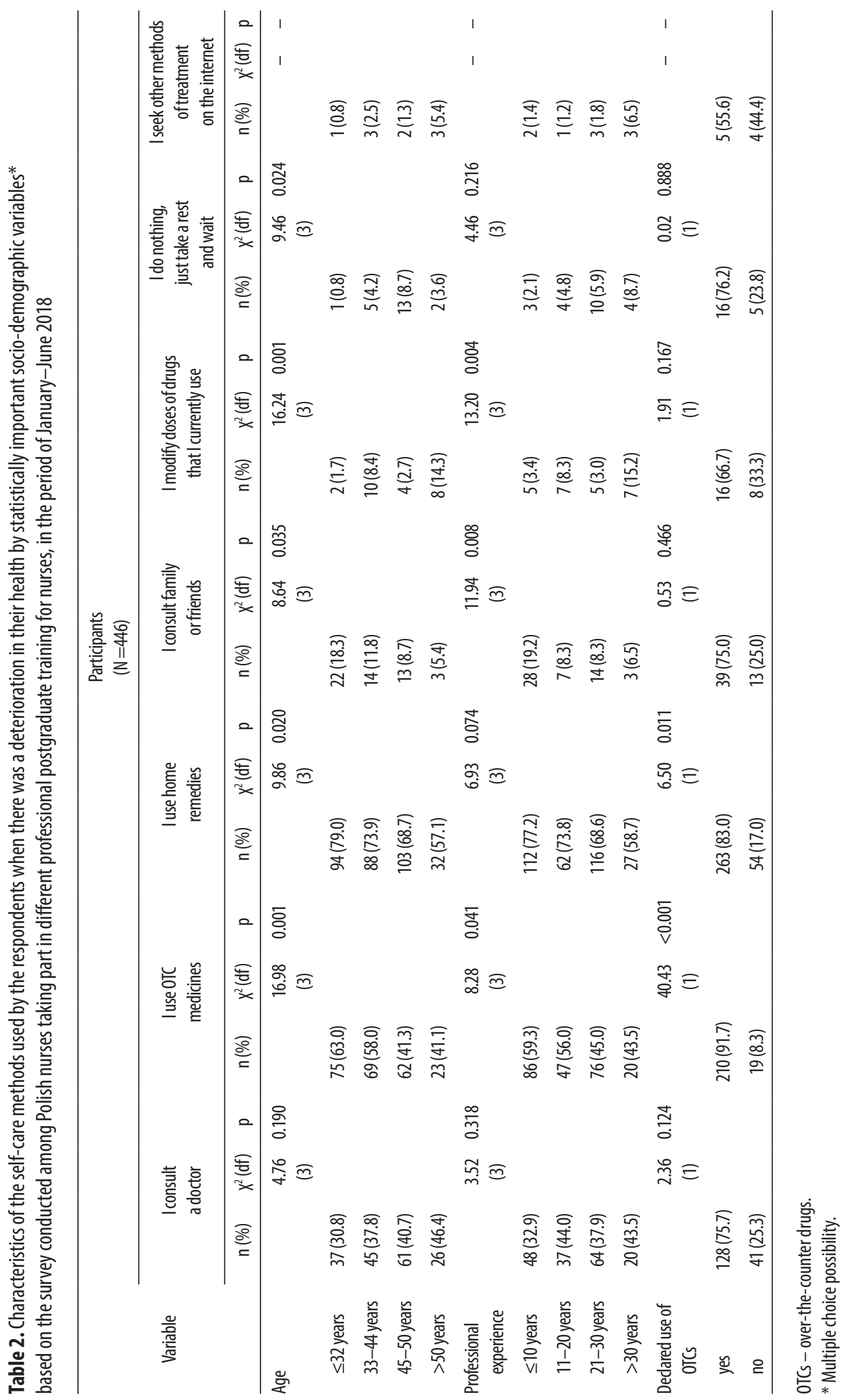


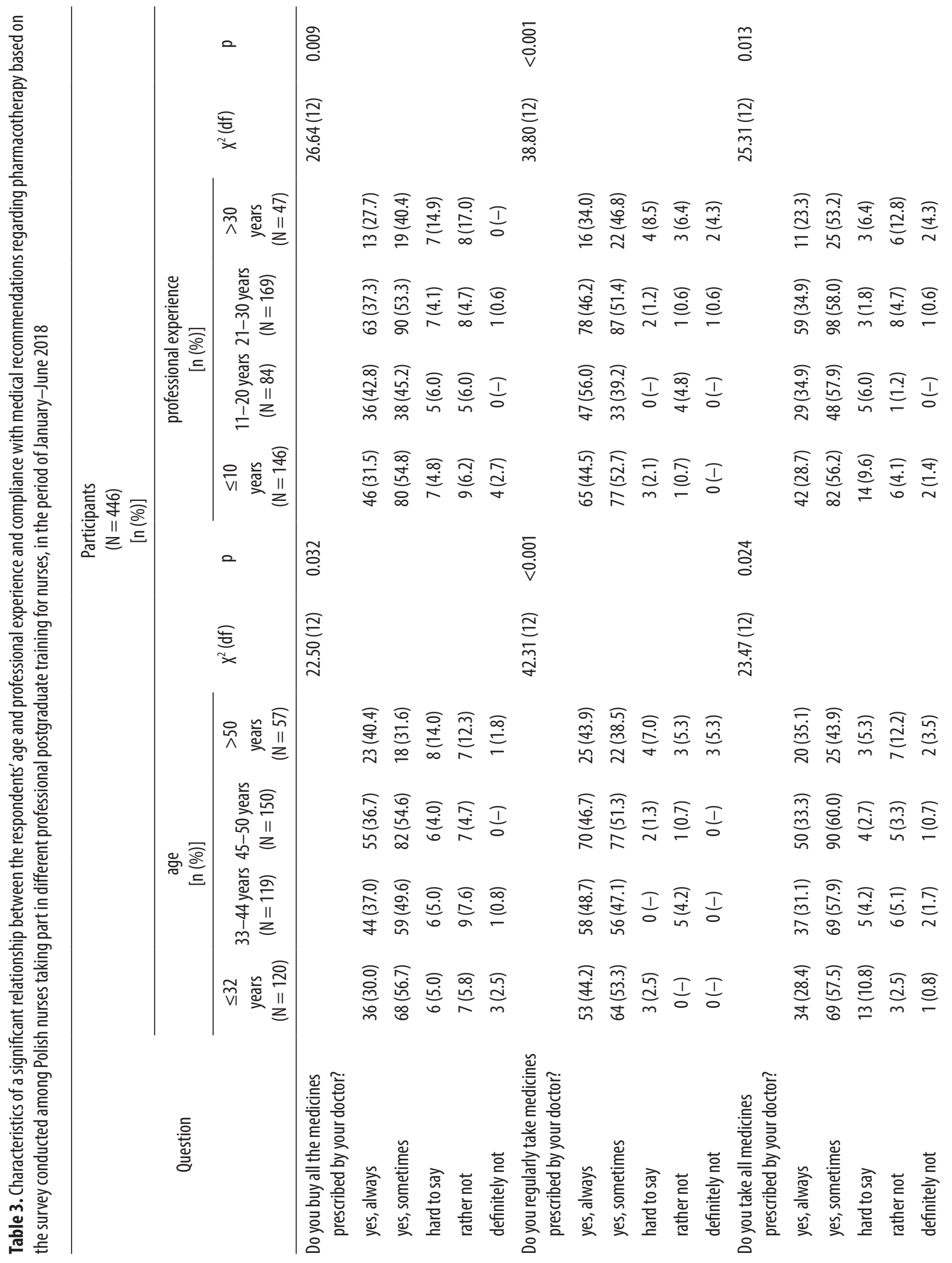




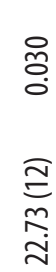

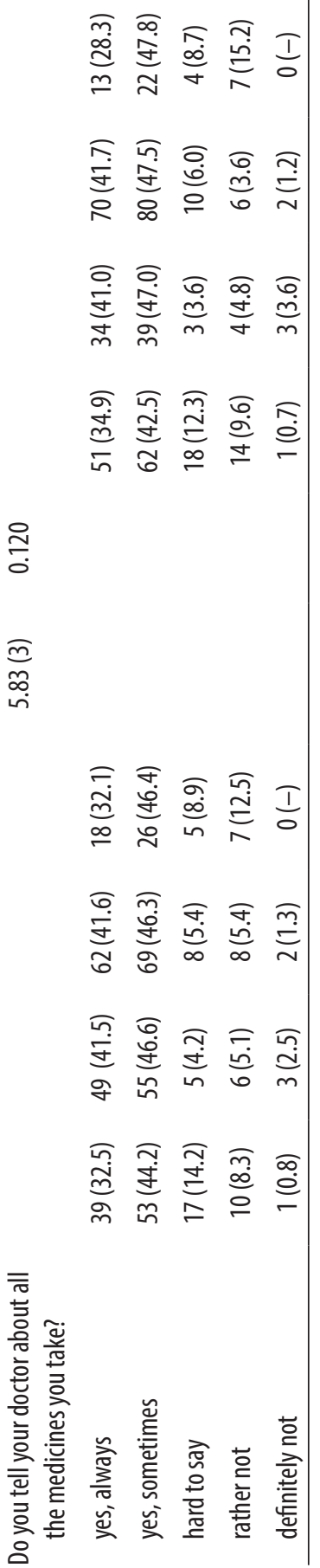

they did it "sometimes." Among the provided reasons, the participants quoted: experienced side effects (38.1\%); too long duration of the treatment (28.6\%); and no expected relief (33.3\%). None of the analyzed socio-demographic and professional variables influenced the results $(\mathrm{p}>0.05)$.

About half of the respondents confirmed that they told the doctor about all the medicines they were taking ("sometimes" - 45.8\%; "always" - 37.9\%). Those who usually or even always did not do it (8.4\%) provided the following explanations: the doctor didn't ask (83.3\%); or it was not important (16.7\%). The respondents' professional experience influenced the results (Table 3).

\section{Dietary supplements use}

With regard to the declared use of supplements, most participants denied taking supplements in any form (69.0\%). The most common reasons provided by those using supplements were deficiencies in vitamins and minerals (77.5\%), boosting the immune system (49.3\%), preventing osteoporosis (27.5\%), stress relief (16.7\%), improving memory, concentration and vitality (12.3\%), improving heart and cardiovascular health (10.1\%), supporting slimming (5.1\%), improving the strength and appearance of hair and nails (3.6\%), and slowing down the ageing process $(2.2 \%)$. The median number of declared reasons was 2 (1-7 reasons).

The most popular supplements included packs of vitamins $(57.2 \%)$, single vitamin $\mathrm{D}_{3}(33.3 \%)$ and magnesium $(31.2 \%)$. The sources of information that encouraged the use of supplements were the participants' own knowledge (54\%) and their previous positive experiences (27.3\%), recommendation by a physician $(21.6 \%)$, recommendation by family and friends (14.4\%), drug advertising (5\%), and recommendation by a pharmacist (3.6\%). With regard to the potential risks of where these supplements were purchased, $85.9 \%$ of the participants denied using such sources. Out of the 63 participants who 
Table 4. Analysis of the significant relationship between OTC use in the last 6 months and selected socio-demographic variables, based on the survey conducted among Polish nurses taking part in different professional postgraduate training for nurses, in the period of January-June 2018

\begin{tabular}{|c|c|c|c|c|}
\hline \multirow[t]{2}{*}{ Variable } & \multicolumn{2}{|c|}{$\begin{array}{c}\text { Participants } \\
(\mathrm{N}=446) \\
{[\mathrm{n}(\%)]}\end{array}$} & \multirow[t]{2}{*}{$X^{2}(d f)$} & \multirow[t]{2}{*}{$p$} \\
\hline & OTC use & no OTC use & & \\
\hline Age & & & $11.28(3)$ & 0.010 \\
\hline$\leq 32$ years & $104(86.7)$ & $16(13.3)$ & & \\
\hline $33-44$ years & $100(84.0)$ & $19(16.0)$ & & \\
\hline $45-50$ years & $113(75.3)$ & $37(24.7)$ & & \\
\hline$>50$ years & $39(68.4)$ & $18(31.6)$ & & \\
\hline Marital status & & & $10.32(4)$ & 0.035 \\
\hline single & $57(82.6)$ & $12(17.4)$ & & \\
\hline married & $236(80.5)$ & $57(19.5)$ & & \\
\hline separated/divorced & $37(80.4)$ & $9(19.6)$ & & \\
\hline widow/widower & $4(40.0)$ & $6(60.0)$ & & \\
\hline living with partner & $18(78.3)$ & $5(21.7)$ & & \\
\hline Professional experience & & & $9.12(3)$ & 0.028 \\
\hline$\leq 10$ years & $126(86.3)$ & $20(13.7)$ & & \\
\hline $11-20$ years & $70(83.3)$ & $14(16.7)$ & & \\
\hline $21-30$ years & $124(73.4)$ & $45(26.6)$ & & \\
\hline$>30$ years & $36(76.6)$ & $11(23.4)$ & & \\
\hline Economic status & & & $9.89(2)$ & 0.007 \\
\hline excellent & $33(76.7)$ & $10(23.3)$ & & \\
\hline good & $215(85.0)$ & $38(15.0)$ & & \\
\hline average and below & $106(72.1)$ & $41(27.9)$ & & \\
\hline
\end{tabular}

Abbreviation as in Table 2.

confirmed their use in the last 6 months, $61.4 \%$ bought supplements online, $24.6 \%$ through direct sales, $8.6 \%$ using advertisements in the press, $5.7 \%$ in gyms, and $2.9 \%$ at bazaars.

\section{Use of OTCs}

With regard to the use of OTCs, $79.8 \%$ of the participants took some kind of OTCs in the last 6 months. The median use was 4 OTC medicines (1-24 OTC medicines) and it depended on the participants' age $\left(\mathrm{p}=0.018 ; \chi^{2}=10.08\right)$. The participants aged $45-50$ years used statistically more
OTCs than those aged 33-44 years. The analysis also showed a statistically significant relationship between the declared OTC use and the respondents' age, marital status, years of professional experience and economic status (Table 4).

Among the most common ailments treated by OTCs, the participants listed headaches (50.7\%), flu (38.6\%) and ailments associated with menstruation (11.5\%). The factors affecting OCTs consumption included considering the illness as an unimportant issue (54.5\%), success of previous self-medication (51.8\%), time constraints (30.2\%), 
limited access to healthcare, especially long waiting times for medical consultations (13.4\%), a lack of satisfaction with the support from a physician (7.4\%), no money to buy the prescription drugs (1.1\%), and emergency situations $(0.8 \%)$. Taking into account the sources of information about OTCs, the following were listed: drug leaflets (54.2\%), work colleagues (47.2\%), pharmacists (36.7\%), TV and the Internet (25.2\%), physicians (20.6\%), family and friends (17.3\%), and one's own knowledge (0.6\%). Almost all the participants confirmed that they obtained this information always or usually before using OTCs (90\%).

Moreover, $26.9 \%$ of the study participants declared using both supplements and OTCs, while $16.4 \%$ of the participants used neither supplements nor OTCs. A significant relationship was found between denying the use of supplements and OTCs, and the participants' age ( $\mathrm{p}=0.043$, $\left.\chi^{2}=8.17\right)$ and professional experience $\left(\mathrm{p}=0.050, \chi^{2}=\right.$ 7.79). The older the nurses were, the more frequently they denied using both supplements and OTCs. Furthermore, the nurses who had worked 21-30 years most often confirmed that they used neither supplements nor OTCs (21.9\%). The overall data regarding the supplements and OTC use is presented in Figure 1.

\section{DISCUSSION}

Nursing is a very challenging profession, both physically and mentally. A high workload, busy environments and constantly increasing client expectations, combined with nursing shortages, can lead to tiredness and exhaustion $[17,18]$. Nurses spend their working hours caring for others; however, if they are not caring for themselves, they cannot care for others. As researchers report, a lack of care with regard to oneself can potentially harm the quality of care $[7,19]$. A few studies have found that self-care strategies are generally poor in this professional group [6,9]. The purpose of this study was to explore the self-care strategies undertaken by Polish nurses. Cur-

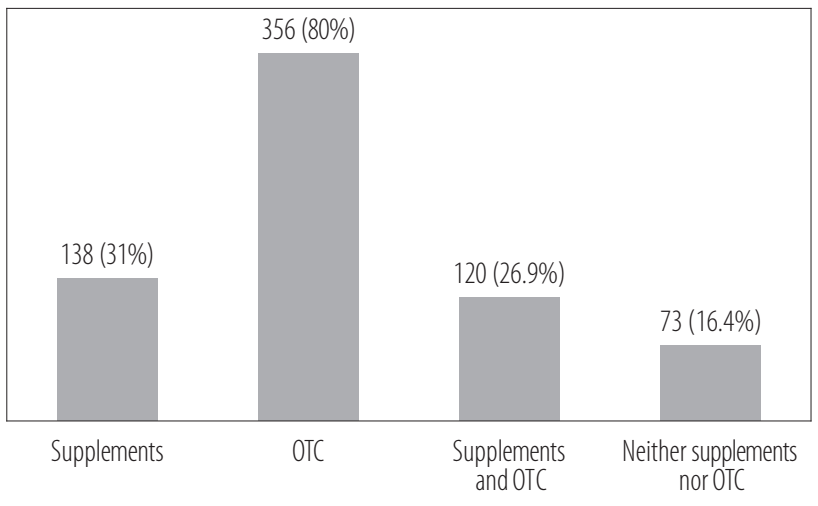

Figure 1. Supplements and over-the-counter drugs (OTCs) use based on number of answers given (multiple choice)

rently, most Polish nurses are between $45-50$ years old and, as in many other countries, further age increases in this professional group are predicted [20]. One can expect that the ageing process may easily lead to health concerns among nurses, which in turn can reduce their quality of life. In this study, $26 \%$ of the participants reported a wide range of diagnoses, with the most common being metabolic and circulatory system disorders. However, the vast majority of nurses (82.5\%) self-assessed their condition of health as "good" or even "very good," which is in line with what the HNHN study confirmed [9].

Effective self-care strategies include a range of health behaviors such as healthy diet, adequate sleep, moderate alcohol intake, physical activity, rest and relaxation, and positive relationships with friends and family [21,22]. The study results suggest that as far as the intentional activities undertaken by nurses are concerned, the most frequent were caring for personal hygiene and a healthy diet. Only about half of the participants performed active recreation and even fewer reported adequate sleep quality and a regular lifestyle. The results of the study by Leão et al. [7] were in agreement with these findings. The authors reported that the participants (female health professionals, mostly nurses) generally neglected self-care, with inadequate hours of sleep (74\%), irregular physical activity (68\%) and inadequate nutrition (45\%). 
In their study, Mills et al. [21] identified some self-care barriers and enablers. Among the most common barriers listed by the respondents were busyness, workplace culture, bringing work home or a lack of planning for selfcare. Meanwhile, the most important enablers included, first of all, recognizing the importance of self-care, positive workplace cultures supportive of self-care, selfawareness, self-compassion, authenticity and courage.

Self-care is also usually the first treatment used for common ailments. Knowing when to consult a healthcare professional is also necessary in order to make appropriate health decisions [3]. The study results suggest that the younger the nurses were and the shorter their seniority, the more often they chose such methods as using OTC medicines, using home remedies, and consulting family or friends when there was a deterioration in their health. A similar pattern for the whole Polish population has been described in other studies [15,23]. Furthermore, some authors concluded that with regard to the nursing profession, having an educational background and contact with a clinical environment can sometimes create false confidence in young nurses that can even be dangerous for a person if they wait for too long before seeking medical help, or if they use treatment that is harmful $[2,24]$.

\section{Dietary supplements use}

Research shows that the number of people using supplements is constantly increasing. This probably mirrors modern times, in which people want to be fit, healthy and good-looking for as long as possible. According to some studies, approx. 22\% of Polish people admit taking supplements. The study results confirmed dietary supplements use in about $31 \%$ of nurses. It is widely known that the use of supplements is associated with such factors as being a woman of middle age to early old age, highly educated, with a good level of income, with knowledge of medications, and focused on paying attention to one's own health $[10,25]$. In their studies, some Polish authors confirmed that the most common reasons for taking supplements concerned the prevention of vitamin and mineral deficiencies and boosting of the immune system. Additionally, women and young people more often pointed to slimming support as an important reason $[11,13,15]$. These results were largely in accordance with these study findings.

As far as the sources of information encouraging the use of supplements are concerned, the nurses most often quoted their own knowledge (54\%) and previous positive experiences with the use of supplements (27.3\%). Recommendation by a physician or family and friends was a less frequently provided reason, while drug advertising and recommendation by a pharmacist were rarely mentioned. These results are in line with the conclusions made by Karbownik et al. [26]. The authors revealed that the overall trust in dietary supplements advertising is low among general public, which can be seen as an intriguing phenomenon in light of the fact that these products are very popular.

\section{Use of OTCs}

Poland is a country with a relatively high OTC consumption [23,27]. With regard to self-medication patterns among such a specific group as healthcare staff, researchers point out that its prevalence is quite high [28]. In nurses, the reality of often busy workdays when they face difficult moments and crises may lead to the conclusion that medication can be a way to make their lives easier [25].

According to the analysis of Polish patterns of OTC consumption, it was revealed that the most frequently used OTCs were analgesics, followed by anti-inflammatory and anti-rheumatic drugs, which is consistent with international results $[23,29]$. The analysis also showed that the consumption of drugs that relieve allergies has increased among Polish consumers in recent years [30]. The study results suggest that the vast majority of the participants (79.8\%) took some kind of OTCs in the last 
6 months, most often painkillers and flu medications. Further, there was no significant relationship between the declared self-care strategies and OTC use.

Some studies showed that the most important sources of information about medicines for nurses were physicians, books, medicine leaflets, and the participants' own knowledge and experiences $[28,29]$. In this study, drug leaflets, work colleagues and pharmacists were the 3 most frequently listed sources of information about OTCs. The physician was the most important source of information for only about $20 \%$ of the participants.

\section{Study limitations}

This study has several limitations. The first limitation lies in the way the study sample was collected and in the relatively small sample size, which could hinder the generalization of the results. However, although their findings are not generalizable, the authors believe that they offer a valuable insight into the health behaviors of Polish nurses.

Self-assessment is another limiting factor. The obtained retrospective data may be biased since the information regarding self-care strategies might be misremembered. To minimize that recall bias, the authors adopted an approach successfully used in previous studies and asked participants to limit their recall to the past 6 months.

The third limitation concerns the possible misunderstanding of the terms OTC and supplement. To avoid this problem, each questionnaire was accompanied by a covering letter in which the participants were informed about the aim of the study and given a glossary of terms.

\section{CONCLUSIONS}

It is obvious that for nurses self-care should not be seen as a selfish luxury, but as an essential factor in their positive therapeutic relationship with patients. However, the findings of this study add to the body of literature that reveals generally poor self-care strategies and compliance with medical recommendations among Polish nurses. Most of them use OTC medicines on a daily basis, relying most often on the information included on the drug leaflets. With regard to supplements consumption, the pattern of use was comparable with the results for the whole population. The ageing nursing workforce should make us increasingly aware that their self-care needs will increase as well.

\section{REFERENCES}

1. Abreu W, Barroso C, Segadães M, Teixeira S. Promotion of self-care in clinical practice: implications for clinical supervision in nursing. Int J Inf Educ Technol. 2015;5(1):6-9, https://doi.org/10.7763/IJIET.2015.V5.466.

2. Chambers R. The role of the health professional in supporting self-care. Qual Prim Care. 2006;14:129-31.

3. Webber D, Guo Z, Mann S. Self-care in health: we can define it, but should we also measure it? Self Care. 2013;4(5):101-6. 4. International Self-Care Foundation [Internet]. London, The Charity Foundation; 2020 [cited 2020 Jun 10]. What is selfcare? Available from: https://isfglobal.org/what-is-self-care/.

5. Purcell C, Moyle W, Evans K. An exploration of modifiable health associated risk factors within a cohort of undergraduate nursing students. Contemp Nurse. 2006;23(1):100-10, https://doi.org/10.5172/conu.2006.23.1.100.

6. Gabrielle S, Jackson D, Mannix J. Older women nurses: health, ageing concerns and self-care strategies. J Adv Nurs. 2008;61(3):316-25, https://doi.org/10.1111/j.1365-2648.2007. 04530.x.

7. Leão ER, Dal Fabbro DR, Oliveira RB, Santos IR, Victor ED, Aquarone RL, et al. Stress, self-esteem and well-being among female health professionals: A randomized clinical trial on the impact of a self-care intervention mediated by the senses. PLoS ONE. 2017;12(2):e0172455, https://doi.org/10.1371/ journal.pone.0172455.

8. Fiabane E, Dordoni P, Setti I, Cacciatori I, Grossi Ch, Pistarini $\mathrm{C}$, et al. Emotional dissonance and exhaustion among healthcare professionals: the role of the perceived quality of care. Int J Occup Med Environ Health. 2019;32(6):841-51, https://doi.org/10.13075/ijomeh.1896.01388. 
9. Gould L, Carpenter H, Farmer DR, Holland D, Dawson JM. Healthy Nurse, Healthy Nation ${ }^{\mathrm{TM}}$ (HNHN): Background and first year results. Appl Nurs Res. 2019;49:64-9, https:// doi.org/10.1016/j.apnr.2019.04.001.

10. Ghazali E, Mutum D, Ching LL. Dietary supplement users vs non-users in Malaysia: Profile Comparisons For Marketing Purposes. In: Welsh DHB, Shukri Ab Yajid M, Pashtenko VH, Ahmed ZU, editors. Advances in Global Business Research. Proceedings of AGBA 3rd World Congress; 2006 Jan 4-6; Kuala Lumpur, Malaysia. Geneva: Inderscience Publishing Co. of Switzerland and UK: 2006. p. 43-54.

11. Wawryk-Gawda E, Budzyńska B, Lis-Sochocka M, Chylińska-Wrzos P, Zarobkiewicz M, Jodłowska-Jędrych B. Dietary supplements - consumer assessment based on questionnaire survey. Epidemiol Rev. 2018;72(1):93-103.

12. Marzec A, Skrzypek M, Marzec Z. Dietary supplements as a challenge for contemporary public health:scale of the phenomenon, health risk, legal regulations. Pol J Publ Health. 2018;128(1):30-5, https://doi.org/10.2478/pjph-2018-0006.

13. Przysławski J, Stępczak M, Reszelska M, Wichura-Demska A. The level of knowledge on dietary supplements among patients of pharmacies in the Greater Poland region. J Med Sci. 2016;85(4):301-6, https://doi.org/10.20883/jms.2016.174.

14. Zboralska M. Polish legal regulations on marketing of food supplements. Europ Food Feed Law Rev. 2012;7(4):188-200.

15. Bochenek T, Godman B, Lipowska K, Mikrut K, Zuziak S, Pedzisz M, et al. Over-the-counter medicine and dietary supplement consumption among academic youth in Poland. Expert Rev Pharmacoeconomics Outcomes Res. 2016; 16(2):199-205, https://doi.org/10.1586/14737167.2016.11 54790.

16. Hys K. Healthcare products and food supplements in Poland - a comparison. MATEC Web Conf. 2018;183:01006, https://doi.org/10.1051/matecconf/201818301006.

17. Galdikienė N, Asikainen P, Balčiūmas S, Suominen T. Do nurses feel stressed? A perspective from primary health care. Nurs Health Sci. 2014;16:327-34, https://doi.org/10.1111/ nhs. 12108 .
18. Kharatzadeh H, Alavi M, Mohammadi A, Visentin D, Cleary M. Emotional regulation training for intensive and critical care nurses. Nurs Health Sci. 2020;1-9, https:/doi. org/10.1111/nhs.12679.

19. Fereira ES, Souza MB, Souza NVDO, Tavares KFA, Pires AS. The importance of self-care for nursing professionals. Ciência Cuidado Saúde. 2015;14(1):978-85, https://doi.org/10.4025/ cienccuidsaude.v14i1.23360.

20. Haczyński J, Skrzypczak Z, Winter M. Nurses in Poland immediate action needed. Eng Manag Pro Serv. 2017;9(2): 97-104.

21. Mills J, Wand T, Fraser JA. Exploring the meaning and practice of self-care among palliative care nurses and doctors: a qualitative study. BMC Palliat Care. 2018;17:6, https://doi. org/10.1186/s12904-018-0318-0.

22. Ross A, Bevans M, Brooks AT, Gibbons S, Wallen GR. Nurses and health-promoting behaviours: knowledge may not translate into self-care. AORN. 2017;105(3):267-75, https:// doi.org/10.1016/j.aorn.2016.12.018.

23. Turek A, Owczarek A. Determinants of consumption behaviour of over-the-counter medications - the case of painkillers and anti-inflammatory medications. J Econ Manag. 2014;15:25-59.

24. Soroush A, Abdi A, Andayeshgar B, Vahdat A, Khatony A. Exploring the perceived factors that affect self-medication among nursing students: a qualitative study. BMC Nurs. 2018;17:35, https://doi.org/10.1186/s12912-018-0302-2.

25. Barros AR, Griep RH, Rotenberg L. Self-medication among nursing workers from public hospitals. Rev Lat-Am Enferm. 2009;17(6):1015-22, https://doi.org/10.1590/s010411692009000600014.

26. Karbownik MS, Paul E, Nowicka M, Nowicka Z, Kowalczyk RP, Kowalczyk E, et al. Knowledge about dietary supplements and trust in advertising them: Development and validation of the questionnaires and preliminary results of the association between the constructs. PLoS ONE. 2019;14(6):e0218398, https://doi.org/10.1371/journal.pone. 0218398. 
27. Wójta-Kempa M, Krzyżanowski DM. Correlates of abusing and misusing over-the-counter pain relievers among adult population of Wrocław (Poland). Advances Clin Exp Med. 2016;25(2):349-60, https://doi.org/10.17219/acem/58887.

28. Davarani RB, Mahmoudvand H, Jamshidi E, Jahani Y, Amirheidari B, Borhaninejad VR, et al. Self-medication among health staff: A cross sectional study of Kerman Province, Iran. Der Pharm Lett. 2016;8(12):221-8.
29. Limaye D, Limaye V, Krause G, Fortwengel G. A systematic review of the literature to assess self-medication practices. Ann Med Health Sci Res. 2017;7:1-15.

30. Zaprutko T, Koligata D, Michalak M, Wieczorek M, Józiak M, Ratajczak M, et al. Misuse of OTC drugs in Poland. Health Policy. 2016;120(8):875-81, https://doi.org/10.1016/ j.healthpol.2016.06.008.

This work is available in Open Access model and licensed under a Creative Commons Attribution-NonCommercial 3.0 Poland License - http://creativecommons.org/ licenses/by-nc/3.0/pl/deed.en. 